\title{
Analysis of an Automatic Control System for the Blending of Petrol with Corrosion Inhibitor in Cranked, Direct Continuous Electronic Fuel Injection (DC-EFI) Automobile Engines
}

\author{
Chigbo A. Mgbemene a,*, Abraham C. Kalu-Uka ${ }^{a}$, \\ Anthony O. Odukwe ${ }^{\text {a }}$ \\ ${ }^{a}$ Department of Mechanical Engineering, University of \\ Nigeria, Nsukka, Nigeria \\ Godwin M. Kalu-Uka ${ }^{\text {, }}$ \\ ${ }^{\mathrm{b}}$ Department of Mechanical and Mechatronic Engineering, \\ Alex Ekwueme Federal University, Ndufu-Alike Ikwo, \\ Ebonyi State, Nigeria
}

\begin{abstract}
This work analyzed the performance of an automatic control system for the blending of petrol with additive (corrosion inhibitor) in a cranked, direct continuous electronic fuel injection automobile engine. The automatic control system was designed by superimposing a feedforward control system on a feedback control system. The design of the automatic control system was analysed by the method of direct substitution. The governing equations used in analysing the blending process, as well as the applicable equations which modelled the process disturbance were derived from first principles - using transfer functions and block diagram representations. The performance of the automatic control system was simulated with the aid of computer software; and the results obtained from the simulation showed that both the response of the blending process and the performance of the automatic control system were oscillatory and stable.
\end{abstract}

Keywords: Corrosion inhibitor; automatic control system; blending process; feedforward control system; feedback control system.

\subsection{INTRODUCTION}

The focus of recent technological revolution in the design of automobiles towards addressing the emissions and power output problem has dwelt mainly on the fuel flow system, air intake systems and how the fuel is delivered to the injector. Researchers have sought solutions that would not require serious modifications to the engine design. The objectives have been on emissions control and power output. Poor quality of fuel has also been studied but it seems that an equal emphasis has not been placed on it as has been placed on the fuel flow system, air intake systems and how the fuel is delivered to the injector. It is necessary that more emphasis should also be placed here. In fact, a lot of engine problems are traceable to the quality of fuel [1 6]. Poor emissions and low power output are directly related to the quality of fuel. Poor quality of fuel is a worldwide problem and is mostly due to the adulteration of the fuel. The effect is more devastating in the developing

\author{
Ikechukwu C. Ezema ${ }^{\mathrm{c}}$, \\ ${ }^{c}$ Department of Metallurgical and Materials Engineering, \\ University of Nigeria, Nsukka, Nigeria \\ Cosmas U. Ogbuka ${ }^{\mathrm{d}}$ \\ ${ }^{\mathrm{d}}$ Department of Electrical Engineering, \\ University of Nigeria, Nsukka, Nigeria
}

world where emissions control is lax and power output problem is not taken seriously.

A lot of studies have been carried out in order to address the problems and improve the performance of the automobile engines. They include the following studies: Payri et al. [7] developed a one-dimensional model of the injector on GT-SUITE software. The hydraulic results obtained from their model showed a good alignment with the experiments for single injections and a varied degree of success for multiple injections. Kimura et al. [8] reported that slowed initial combustion can be recovered if the turbulent intensity is increased by means of the spray induced air motion. El-Kassaby et al. [9] evaluated the effect of addition of hydroxyl gas HHO into the gasoline fuel as an engine performance improver. $\mathrm{Ma}$ et al. [10] showed that blending $\mathrm{H}_{2}$ and natural gas (NG) achieved shorter flame development and propagation periods thereby enhancing the combustion efficiency and lowering emission level. Shivaprasad et al. [11] reported that with an increase in $\mathrm{H}_{2}$ fraction in the fuel, there was a decrease in the brake mean effective pressure, $B_{\text {mep }}$, and thermal efficiency, as well as a decrease in both $\mathrm{HC}$ and $\mathrm{CO}$ emissions. Wang et al. [12] reported that $\mathrm{H}_{2}$ fraction would control the diameter of particulate emissions. They also reported that an almost constant $\mathrm{CO}$ emission would be obtained irrespective of the hydrogen fraction as it changed from $0-100 \%$. Wang et al. [13] investigated the effect of hydrogen-oxygen blends (hydroxygen) addition on the performance of a spark-ignited (SI) gasoline engine. Their test results showed that the hydroxygen-blended gasoline engine produced higher thermal efficiency and brake mean effective pressure than both of the original and hydrogenblended gasoline engines at lean conditions.

Quite a substantial work has gone into the improvement of the air intake and air handling systems of the automobile engines such as by Chen et al. [14]; Anatone et al. [15], however, many of them are proprietary [16 - 18]. Tuccar et 
al. [19] worked on optimizing the fuel inlet port geometry of an air assisted diesel injector. They aimed at determining the influence of different inlet port geometries on flow characteristics of a specially designed diesel injector which was developed for diesel fuel atomization. They did this by using computational fluid dynamics techniques. Studies on injector nozzle hole parameter and its influence on diesel performance were carried out by Lindsorm [20]. Studies on atomization of the fuel have been carried out by Lorenzetto and Lefebvre [21], Lefebvre [22], and Watanawanyoo et al. [23]. Tuccar et al. [24] investigated the effects of boundary conditions on the flow behaviour in a diesel injector.

Notable studies on the control of the automotive engine include those of Tomizuka and Fung [25] and Sworder [26]. Yang et al. [27] researched on the dynamic modeling and analysis of an automotive multi-port electronic fuel delivery system. The fallout of their research was the development of a multi-port electronic fuel injection system which is capable of analyzing fast fluid transients in the supply of fuel to the automobile engine. Kao and Moskwa [28] presented engine models that are used for nonlinear diesel engine control, state estimation, and model-based diagnostics. Powell et al. [29] in their work developed a model for the idle speed control of a six cylinder electronically fuel injected, spark ignition engine. Archer and Bell [30] designed and developed two advanced fuel injection systems for small vehicles which have become commercially available. The two systems were intended for application on small vehicles fitted with one or two cylinder gasoline engines of displacement 50$250 \mathrm{~cm}^{3}$ per cylinder. The fuel consumption and emission results from both systems showed that the engine exhaust emissions for both systems met the current and future limits on Europe, India and Taiwan, without the need for exhaust after-treatment; and that both systems offered significant fuel savings relative to otherwise-equivalent carbureted baseline vehicles. Yang et al. [31] proposed the combustion concept of multiple premixed compression ignition (MPCI) in gasoline direct injection compression ignition (GDICI) regime. Chung et al. [32] studied the effects of the fuel injection ratio on the emission and combustion performances of the partially premixed charge compression ignition combustion engine applied with the split injection method. Tumbal et al. [33] studied the effect of injection timing, injector opening pressure, injector nozzle geometry, and swirl on the performance of a direct injection, compression-ignition engine fueled with honge oil methyl ester (HOME).

Passarini and Pinotti [34] designed and analyzed a new model of fast-acting electromagnetic fuel injectors. Lee et al. [35] proposed an engine fuel control scheme using fuzzy logic. Lee and his team presented a cost-effective fuzzy control system that was applied to a small spark ignition internal combustion engine to achieve a modest regulation of the fuel injection system.

While conducting an experimental investigation on the electronic fuel injection (EFI) engine in a 2-stroke spark ignition engine, Robinson and Dhandapani [36] used a virtual instrumentation technique to analyse the emission of the EFI engine. They carried out a comparative study of a base engine for determining the effect of electronic fuel injection system, and the results of their study showed that the accurate and precise control of the fuel injection process, through the use of virtual instrumentation, resulted in improved engine performance and reduced emissions. In an attempt to design a control system which could reduce the harmful waste in automobile exhaust emission (by regulating the amount of fuel injected into the combustion chamber), Tan et al. [37] developed a linear model of the dynamics of the internal combustion engine based on a system identification approach which allowed a methodical application of linear control theories.

Mastanaiah [38] analyzed the performance of electronic fuel injection systems using an air compressor and a controller and demonstrated that using an air compressor, instead of an electric fuel pump (to pressurize the fuel in the fuel tank), conserves a significant amount of engine power. At present, most parts in the automobile, such as the propulsion, transmission, braking and safety systems have already been automated and redesigned as the engine management system (EMS), the continuously variable transmission (CVT) system, the antilock braking system (ABS) and the supplement restraint system (SRS) respectively.

These literature, although not exhaustive, demonstrate some of the strides made in the automobile industry in the fuel control system. However, the problem associated with the introduction of adulterate fuel into the engine system remains to be properly addressed. According to CIMAC [1] "the ignition delay of a fuel is correlated with the carbon aromacity of that fuel." Also correlated with carbon aromacity are viscosity and density of the fuel

The adulteration of petroleum products (especially petrol) is the result of a number of anomalies in the processing, storage, pricing and marketing of petroleum products. Specifically, bad bunkering, deliberate inclusion of impurities, blending errors, etc., result in low fuel quality. The use of petrol additives has been suggested as a safeguard against the harmful effect of petrol adulteration in automobile engines [39]. However, it was observed that the prescriptions given by most manufacturers of petrol additives were vague and bereft of specific instructions which are necessary for the owners of automobiles to monitor the optimal quantity of the additive which should be applied to the petrol in their tank. Some prescriptions read, "ADD ENTIRE CONTENTS TO A FULL FUEL TANK" regardless of the volume of the petrol tank; but it is obvious that the fuel/additive quantity can only work best at a given mix ratio. Following this, it is necessary to develop a system that specifies and meters out an appropriate amount of additive at any given time.

This work seeks to analyze the prospect for designing an effective automatic control system for the blending of petrol with additive (for example, corrosion inhibitor) in a cranked, direct continuous electronic fuel injection automobile engine. The objective of this work therefore is to design an automatic control system which shall ensure that the blending process is stable (i.e., the composition of the mixture of petrol and corrosion inhibitor remains constant, regardless of any variation in the flow velocity of 
the petrol which is supplied to the automobile engine). The scope of the analysis includes the design of the automatic control system for the blending process; and the derivation of generic expressions for the functions which model the disturbance in the blending process, the stability of the blending process, and the stability of the automatic control system. The stability of both the blending process and the automatic control system for the blending process will be simulated using Simulink $^{\circledR}$ in MATLAB. Due to constraints in financial and material resources, experimental validation of the model will not be embarked on. We do not have access to the high-tech equipment that are required to validate our results. Consequently, the simulation of the control system will only be a simple idealization of the performance of a real-time control process.

\subsection{THE DIRECT CONTINUOUS EFI PROCESS}

The direct, continuous electronic injection of fuel into the automobile engine is a special technology in the design of engine fuel supply systems. The primary factors that determine the quantity of petrol required by an automobile engine are the amount (by weight) of air that is supplied to

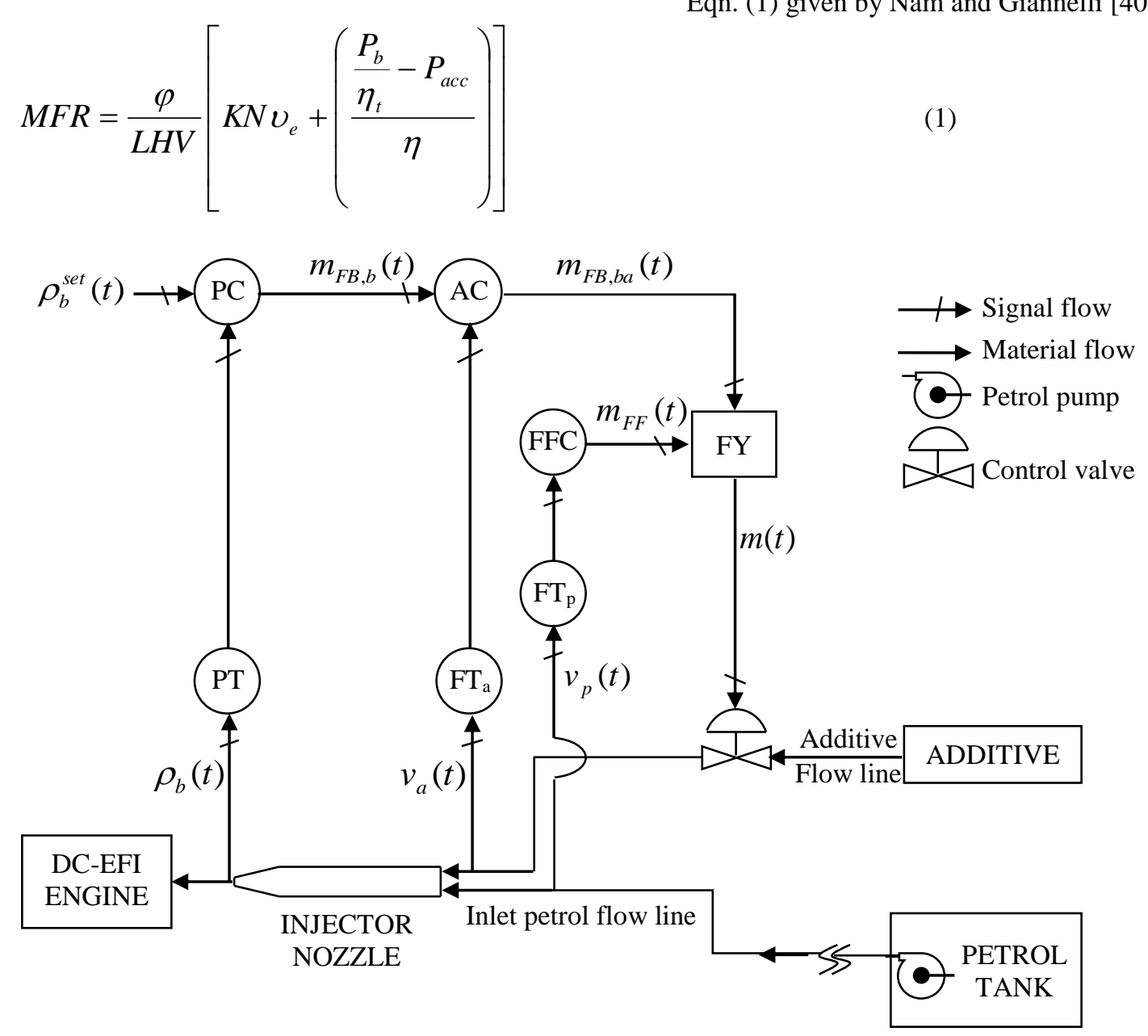

Fig. 1: Schematic diagram of the automatic control system for the online blending of petrol with corrosion inhibitor

\footnotetext{
Fig. 1: Schematic diagram of the automatic control system for the online blending of petrol with corrosion inhibitor
in a direct continuous EFI engine.
}

the engine and the amount of power output desired by the driver (which is expressed in terms of the engine load).

Whereas the amount of air supplied to the engine is monitored by a mass airflow (MAF) sensor; a throttle valve position sensor (TPS) monitors the amount of power output desired by the driver. Both the MAF sensor and the TPS are remotely controlled by the vehicle electronic control unit (ECU). The function of the ECU is to, among other things; interpret data from the MAF sensor and the TPS, in order to calculate the exact amount of petrol that must be injected into the engine.

Looking at Fig. 1 it could be shown that at engine start-up (i.e., at time, $t=t_{0}$ ), highly pressurised petrol is supplied to the engine at a steady flow velocity. As a result, the engine revs at a base speed. The base rpm is just enough to move the car against a certain minimum resistance if the vehicle transmission systems were engaged. Beyond engine startup (i.e., at time, $t>t_{0}$ when the accelerator is pedaled), the petrol pump is signalled by the vehicle ECU to increase the velocity of the inlet petrol which it supplies to the engine. As more petrol is supplied to the engine; the engine burns the petrol to increase its speed and power. The direct relationship between engine speed and the flow velocity of the petrol which is supplied to the engine can be seen in Eqn. (1) given by Nam and Giannelli [40]: 


\subsection{Designing the Automatic Control System}

The automatic control system shown in Fig. 1 is a superposition of a feedforward control loop on a feedback control system. The feedforward control loop compensates for the disturbance in the system before it (the disturbance) affects the controlled variable $\rho_{b}(t)$. At engine start up, i.e., at $t=t_{0}$, petrol is supplied to the engine at a steady velocity. At this velocity, the control valve meters a steady volume of the additive that is sufficient to achieve the correct blend of the petrol and additive. Beyond $t_{0}$ (i.e., whenever the engine is throttled), the ECU sends a signal to the control pump to increase the flow of petrol to the engine. When this happens, the flow transmitter for the inlet petrol, $F T_{p}$ detects the change in the flow velocity of the inlet petrol, $v_{p}(t)$ and sends the signal to the feedforward controller, FFC. When the FFC receives the signal, it calculates a new value for the feedforward manipulated signal, $m_{F F}(t)$ and sends it to the control valve.

The purpose of the feedback control system is to regulate the output/performance of the feedforward controller. In order to do this, the density of the blended petrol is probed by the density sensor/transmitter, PT (just before the blended petrol is injected into the engine). The moment the PT detects a change in the density of the blended petrol, it sends a signal to the density controller, PC, which is

$$
G_{T}(s)=\frac{C(s)}{P V(s)}=\frac{K_{T}}{\tau_{T} s+1}
$$

where

$$
K_{T}=\frac{\text { span of the output signal }}{\text { span of the measured variable }}
$$

responsible for initiating a corrective action to the system. Consequently, whenever the density of the blended petrol is markedly different from the set-point density, $\rho_{b}^{\text {set }}(t)$; the $\mathrm{PC}$ will send an error signal to the additive controller, $\mathrm{AC}$, so as to adjust the velocity of the additive flowing into the blending chamber (i.e., the injector nozzle). The AC is able to control the flow of the additive by using the signal from the sensor /transmitter for the additive flow rate, $\mathrm{FT}_{\mathrm{a}}$, to influence the action of the control valve, via the control system summing device, FY.

\subsection{Choosing the Control System Components}

The basic components of the control system are the sensor/transmitter devices, control valves and the controllers. The sensor/transmitter devices used in this design was modelled from the transfer function of a firstorder lag process as:

The control valves used in the design of the system were equal percentage valves, which operate on a fail-close action. This type of control valve was also modelled from the transfer function of a first-order lag process as:

$$
G_{V}(s)=\frac{F(s)}{M(s)}=\frac{K_{v}}{\tau_{v} s+1}
$$

where

$$
\begin{aligned}
& K_{V}=\frac{\dot{m}(\ln \alpha)}{100} \\
& \dot{m}=\text { mass flow rate of the working fluid } \\
& \alpha=\text { valve rangeability parameter }
\end{aligned}
$$

The valve rangeability parameter, $\alpha$ is theoretically defined as the ratio of the maximum controllable outflow (i.e., when the valve is fully open) to the minimum controllable outflow (i.e., when valve is fully closed). However, the actual value of $\alpha$ for design purposes is computed as the ratio of the valve outflow at $95 \%$ valve position, to the valve outflow at $5 \%$ valve position [41] i.e.

$$
\text { valve rangeability }=\frac{\text { flow at } 95 \% \text { of the fully open valve position }}{\text { flow at } 5 \% \text { of the fully open valve position }}
$$


The controllers for the blending process were proportional integral (PI) controllers and were selected to work in direct action to the change in the flow velocity of the process streams. The transfer function and block diagram representation for PI controllers are:

$$
G_{C}(s)=\frac{M(s)}{E(s)}=K_{C}\left(1+\frac{1}{\tau_{i} s}\right)
$$

\subsection{Modelling the Blending Process}

The following assumptions were made in modelling the blending process:

1. The inlet petrol, corrosion inhibitor and blended petrol are incompressible and non-viscous fluids; with zero boundary layer effects.

2. The injector nozzle is the blending chamber.

3. There is perfect, non-reactive, adiabatic mixing of the inlet petrol and corrosion inhibitor in the blending chamber.

4. The densities of the inlet petrol and corrosion inhibitor are constant at all times, regardless of the differences in the origin and points of sale of the fluids.

5. There is negligible pressure drop along the entire control system pipework (i.e., the pressure in each pipework in the control system is constant).

6. The cross-sectional areas of both the inlet petrol and corrosion inhibitor pipelines are uniform along the entire lengths of the control system pipework.

7. The blending process occurs at constant temperature. Hence, there is no mass transfer due to temperature-induced concentration gradient.

8. The blending process must be a linear process so that the process parameters could either be constant terms, or variables which could be assigned arbitrary steady-state values [41].

9. The input and output signals of the individual components of the automatic control system must be linear functions [41].

10. The effect of process dead time, owing to transportation lag, is negligible.

11. The process variables are deviations from the initial, steady-state initial conditions [41].

12. The process variables are functions of time only.

13. The major disturbance in the blending process is the change in the flow velocity of the inlet petrol.

14. All the input variables for the blending process must be known variables [41].

15. The reference frame of the control volume is nonaccelerating.

16. The volume of the petrol-additive mixture in the blending chamber does not vary with time (i.e., the blending chamber is always filled with the mixture of petrol and additive).

A good place to do the blending of the fluids will be in the injector nozzle; hence, the control volume for the modelling will be in the injector nozzle. Figure 2 is a control volume representation of the blending process.

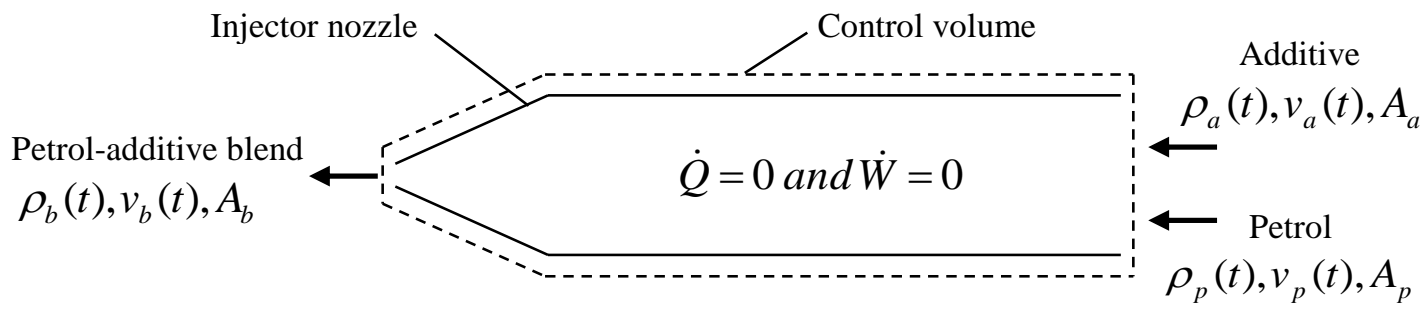

Fig.2: Control volume representation of the blending process.

Applying the conservation of mass equation to the control volume, we have that:

$$
v \frac{d \rho_{b}(t)}{d t}=A_{p} \rho_{p} v_{p}(t)+A_{a} \rho_{a} v_{a}(t)-A_{b} \rho_{b}(t) v_{b}(t)
$$

When linearized at the initial steady state conditions, we obtain

$$
\tau_{1}=\frac{d P_{b}(t)}{d t}+P_{b}(t) \approx K_{11} V_{p}(t)+K_{12} V_{a}(t)+K_{13} V_{b}(t)
$$

where

$\tau_{1}=$ time constant for the conservation of mass in the blending process $=\frac{v}{A_{b} \bar{v}_{b}}$ 
$K_{11}=$ steady state gain for the conservation of mass in the blending process with respect to changes in $V_{p}(t)=\frac{A_{p} \rho_{p}}{A_{b} \bar{v}_{b}}$ $K_{12}=$ steady state gain for the conservation of mass in the blending process with respect to changes in $V_{a}(t)=\frac{A_{a} \rho_{a}}{A_{b} \bar{v}_{b}}$ $K_{13}=$ steady state gain for the conservation of mass in the blending process with respect to changes in $V_{b}(t)=-\frac{\bar{\rho}_{b}}{\bar{v}_{b}}$ Equation 8 is then transformed into a Laplace function to obtain

$$
\left(\tau_{1} s+1\right) P_{b}(s) \approx K_{11} V_{p}(s)+K_{12} V_{a}(s)+K_{13} V_{b}(s)
$$

and

$$
P_{b}(s) \approx \frac{K_{11}}{\left(\tau_{1} s+1\right)} V_{p}(s)+\frac{K_{12}}{\left(\tau_{1} s+1\right)} V_{a}(s)+\frac{K_{13}}{\left(\tau_{1} s+1\right)} V_{b}(s)
$$

The conservation of $\mathrm{x}$-momentum equation for the control volume is:

$$
\sum \mathrm{F}_{\mathrm{x}}=v \frac{d}{d t}\left[\rho_{b}(t) v_{b}(t)\right]+A_{b} \rho_{b}(t) v_{b}^{2}(t)-A_{p} \rho_{p} v_{p}^{2}(t)-A_{a} \rho_{a} v_{a}^{2}(t)
$$

Since there is no resultant force acting on the control volume then:

$$
\begin{aligned}
& v \frac{d}{d t}\left[\rho_{b}(t) v_{b}(t)\right]+A_{b} \rho_{b}(t) v_{b}^{2}(t)-A_{p} \rho_{p} v_{p}^{2}(t)-A_{a} \rho_{a} v_{a}^{2}(t)=0 \\
& \frac{d \rho_{b}(t)}{d t}=\frac{A_{p} \rho_{p}}{v v_{b}(t)} v_{p}^{2}(t)+\frac{A_{a} \rho_{a}}{v v_{b}(t)} v_{a}^{2}(t)-\frac{\rho_{b}(t)}{v_{b}(t)} \frac{d v_{b}(t)}{d t}-\frac{A_{b} \rho_{b}(t)}{v} v_{b}(t)
\end{aligned}
$$

To find an expression for the rate of change of the flow velocity of the blended petrol with respect to time, $\frac{d V_{b}(t)}{d t}$; we considered the equation for the conservation of energy in the blending process on the assumption the enthalpy of the blended petrol is uniform at all times and noting that $\dot{Q}=0$ and $\dot{W}=0$. We obtained that

$$
\begin{aligned}
\frac{d \rho_{b}(t)}{d t} & =\frac{2 A_{p} \rho_{p} v_{p}(t) h_{p}}{2 v v_{i p} h_{p}+2 v v_{i a} h_{a}+v v_{b}^{2}(t)}+\frac{A_{p} \rho_{p} v_{p}^{3}(t)}{2 v v_{i p} h_{p}+2 v v_{i a} h_{a}+v v_{b}^{2}(t)}+\frac{2 A_{a} \rho_{a} v_{a}(t) h_{a}}{2 v v_{i p} h_{p}+2 v v_{i a} h_{a}+v v_{b}^{2}(t)} \\
& +\frac{A_{a} \rho_{a} v_{a}^{3}(t)}{2 v v_{i p} h_{p}+2 v v_{i a} h_{a}+v v_{b}^{2}(t)}-\frac{2 v \rho_{b}(t)}{2 v v_{i p} h_{p}+2 v v_{i a} h_{a}+v v_{b}^{2}(t)} \frac{d v_{b}(t)}{d t}-\frac{2 A_{b} \rho_{b}(t) v_{b}(t) v_{i p} h_{p}}{2 v v_{i p} h_{p}+2 v v_{i a} h_{a}+v v_{b}^{2}(t)} \\
& -\frac{2 A_{b} \rho_{b}(t) v_{b}(t) v_{i a} h_{a}}{2 v v_{i p} h_{p}+2 v v_{i a} h_{a}+v v_{b}^{2}(t)}-\frac{A_{b} \rho_{b}(t) v_{b}^{3}(t)}{2 v v_{i p} h_{p}+2 v v_{i a} h_{a}+v v_{b}^{2}(t)}
\end{aligned}
$$

Combining Eqns. 13 and 14 we have that 


$$
\begin{aligned}
& \frac{d v_{b}(t)}{d t}=\frac{A_{p} \rho_{p} v_{p}^{2}(t)\left[2 v_{i a} h_{a}+2 v_{i p} h_{p}+v_{b}^{2}(t)\right]}{2 \rho_{b}(t) v v_{i a} h_{a}+2 \rho_{b}(t) v v_{i p} h_{p}+\rho_{b}(t) v v_{b}^{2}(t)-2 v_{b}(t) v \rho_{b}(t)}+\frac{A_{a} \rho_{a} v_{a}^{2}(t)\left[2 v_{i h} h_{a}+2 v_{i p} h_{p}+v_{b}^{2}(t)\right]}{2 \rho_{b}(t) v v_{i a} h_{a}+2 \rho_{b}(t) v v_{i p} h_{p}+\rho_{b}(t) v v_{b}^{2}(t)-2 v_{b}(t) v \rho_{b}(t)} \\
& -\frac{A_{b} v_{b}(t)\left[2 v_{b}(t) v_{i a} h_{a}+2 v_{b}(t) v_{i p} h_{p}+v_{b}^{3}(t)\right]}{2 v v_{i a} h_{a}+2 v v_{i p} h_{p}+v v_{b}^{2}(t)-2 v v_{b}(t)}-\frac{2 A_{p} \rho_{p} v_{p}(t) h_{p}\left[2 v_{b}(t) v_{i a} h_{a}+2 v_{b}(t) v_{i p} h_{p}+v_{b}^{3}(t)\right]}{\left[v_{i a} h_{a}+2 v_{i p} h_{p}+v_{b}^{2}(t)\left[2 \rho_{b}(t) v_{i a} h_{a}+2 \rho_{b}(t) v_{i p} h_{p}+\rho_{b}(t) v_{b}^{2}(t)-2 v_{b}(t) \rho_{b}(t)\right]\right.} \\
& -\frac{A_{p} \rho_{p} v_{p}^{3}(t)\left[2 v_{b}(t) v_{i a} h_{a}+2 v_{b}(t) v_{i p} h_{p}+v_{b}^{3}(t)\right]}{\left[2 v_{i h} h_{a}+2 v_{i p} h_{p}+v_{b}^{2}(t)\left[2 \rho_{b}(t) v_{i a} h_{a}+2 \rho_{b}(t) v_{i p} h_{p}+\rho_{b}(t) v_{b}^{2}(t)-2 v_{b}(t) \rho_{b}(t)\right]\right.} \\
& -\frac{2 A_{a} \rho_{a} v_{a}(t) h_{a}\left[2 v_{b}(t) v_{i a} h_{a}+2 v_{b}(t) v_{i p} h_{p}+v_{b}^{3}(t)\right]}{\left[2 v_{i a} h_{a}+2 v_{i p} h_{p}+v_{b}^{2}(t)\left[2 \rho_{b}(t) v_{i h} h_{a}+2 \rho_{b}(t) v_{\text {ip }} h_{p}+\rho_{b}(t) v_{b}^{2}(t)-2 v_{b}(t) \rho_{b}(t)\right]\right.} \\
& -\frac{A_{a} \rho_{a} v_{a}^{3}(t)\left[2 v_{b}(t) v_{i a} h_{a}+2 v_{b}(t) v_{i p} h_{p}+v_{b}^{3}(t)\right]}{\left[2 v_{i a} h_{a}+2 v_{i p} h_{p}+v_{b}^{2}(t)\left[2 \rho_{b}(t) v_{i a} h_{a}+2 \rho_{b}(t) v_{i p} h_{p}+\rho_{b}(t) v_{b}^{2}(t)-2 v_{b}(t) \rho_{b}(t)\right]\right.} \\
& +\frac{2 A_{b} v_{b}(t) v_{i a} h_{a}\left[2 v_{b}(t) v_{i a} h_{a}+2 v_{b}(t) v_{i p} h_{p}+v_{b}^{3}(t)\right]}{\left.\left[2 v_{i a} h_{a}+2 v_{i p} h_{p}+v_{b}^{2}(t)\right] 2 v_{i a} h_{a}+2 v_{i p} h_{p}+v_{b}^{2}(t)-2 v_{b}(t)\right]}+\frac{2 A_{b} v_{b}(t) v_{\text {ip }} h_{p}\left[2 v_{b}(t) v_{i a} h_{a}+2 v_{b}(t) v_{i p} h_{p}+v_{b}^{3}(t)\right]}{\left[2 v_{i a} h_{a}+2 v_{\text {ip }} h_{p}+v_{b}^{2}(t)\left[2 v_{i a} h_{a}+2 v_{i p} h_{p}+v_{b}^{2}(t)-2 v_{b}(t)\right]\right.} \\
& +\frac{A_{b} v_{b}^{3}(t)\left[2 v_{b}(t) v_{i h} h_{a}+2 v_{b}(t) v_{i p} h_{p}+v_{b}^{3}(t)\right]}{\left[2 v_{\text {ia }} h_{a}+2 v_{i p} h_{p}+v_{b}^{2}(t)\left[2 v_{i a} h_{a}+2 v_{i p} h_{p}+v_{b}^{2}(t)-2 v_{b}(t)\right]\right.}
\end{aligned}
$$

When linearized and transformed into a Laplace Function (and assuming that the initial value of the velocity of the blended petrol $v_{b}(0)$ is equal to the steady state value of the velocity of the blended petrol, $\bar{v}_{b}$ ) we obtain:

$$
\begin{aligned}
& \left(\tau_{2} s+1\right) V_{b}(s) \approx K_{21} V_{p}(s)+K_{22} V_{a}(s)+K_{23} V_{b}(s) \\
& V_{b}(s) \approx \frac{K_{21}}{\left(\tau_{2} s+1\right)} V_{p}(s)+\frac{K_{22}}{\left(\tau_{2} s+1\right)} V_{a}(s)+\frac{K_{23}}{\left(\tau_{2} s+1\right)} V_{b}(s)
\end{aligned}
$$

Using Eqn. 10 to substitute for $V_{b}(s)$ in Eqn. 17

$$
\begin{aligned}
& {\left[1+\frac{K_{13} K_{23}}{\left(\tau_{1} s+1\right)\left(\tau_{2} s+1\right)}\right] P_{b}(s)=\left[\frac{K_{11}}{\tau_{1} s+1}-\frac{K_{13} K_{21}}{\left(\tau_{1} s+1\right)\left(\tau_{2} s+1\right)}\right] V_{p}(s)+\left[\frac{K_{12}}{\tau_{1} s+1}-\frac{K_{13} K_{22}}{\left(\tau_{1} s+1\right)\left(\tau_{2} s+1\right)}\right] V_{a}(s)} \\
& \therefore P_{b}(s)=\left[\frac{K_{11}\left(\tau_{2} s+1\right)-K_{13} K_{21}}{\left(\tau_{1} s+1\right)\left(\tau_{2} s+1\right)+K_{13} K_{23}}\right] V_{p}(s)+\left[\frac{K_{12}\left(\tau_{2} s+1\right)-K_{13} K_{22}}{\left(\tau_{1} s+1\right)\left(\tau_{2} s+1\right)+K_{13} K_{23}}\right] V_{a}(s)
\end{aligned}
$$

Thus, Eqn. 19 is the Laplace transform of the mathematical model of the blending process. The block diagram representation of Eqn. 19 is shown in Fig. 3.

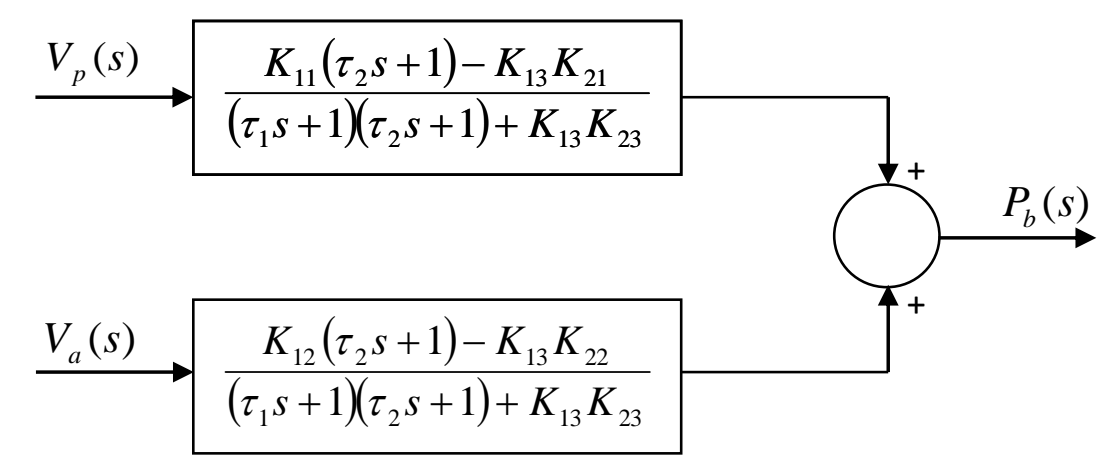

Fig. 3: Block diagram representation of the response of the blending process. 
From the block diagram shown above, the transfer functions for the blending process are:

$$
\begin{aligned}
& \frac{P_{b}(s)}{V_{p}(s)}=\frac{K_{11}\left(\tau_{2} s+1\right)-K_{13} K_{21}}{\left(\tau_{1} s+1\right)\left(\tau_{2} s+1\right)+K_{13} K_{23}}=G_{p}(s) \\
& \frac{P_{b}(s)}{V_{a}(s)}=\frac{K_{12}\left(\tau_{2} s+1\right)-K_{13} K_{22}}{\left(\tau_{1} s+1\right)\left(\tau_{2} s+1\right)+K_{13} K_{23}}=G_{a}(s)
\end{aligned}
$$

\subsection{Modelling the Process Disturbance}

In developing a model for the blending process, it would be observed that to a large extent, to drive an automobile from one point to another, the driver must crank the engine which will definitely rev for a given time frame. The engine revs as the petrol pump discharges a specific amount of petrol into it. This is represented by region A1 in Fig. 4a. When the transmissions are engaged and the engine is throttled, more petrol is delivered to the engine. This is represented by region B1. Region B2 represents a varying of the engine torque by varying the amount of petrol delivered to the engine. At the end of the drive, after a time, $t_{n}$, the driver brings the automobile to a halt with a short period of time in which the engine was allowed to rev. The process around that time is represented by the region A2.

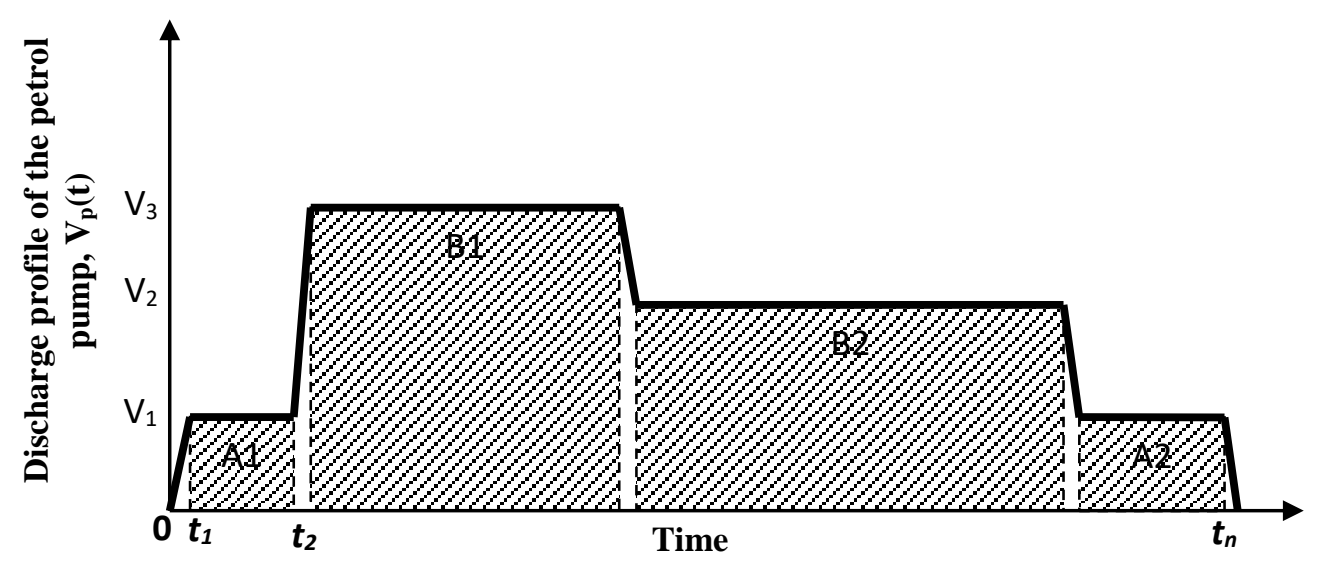

Fig. 4a: Illustration of the velocity profile of the discharge from the petrol pump.

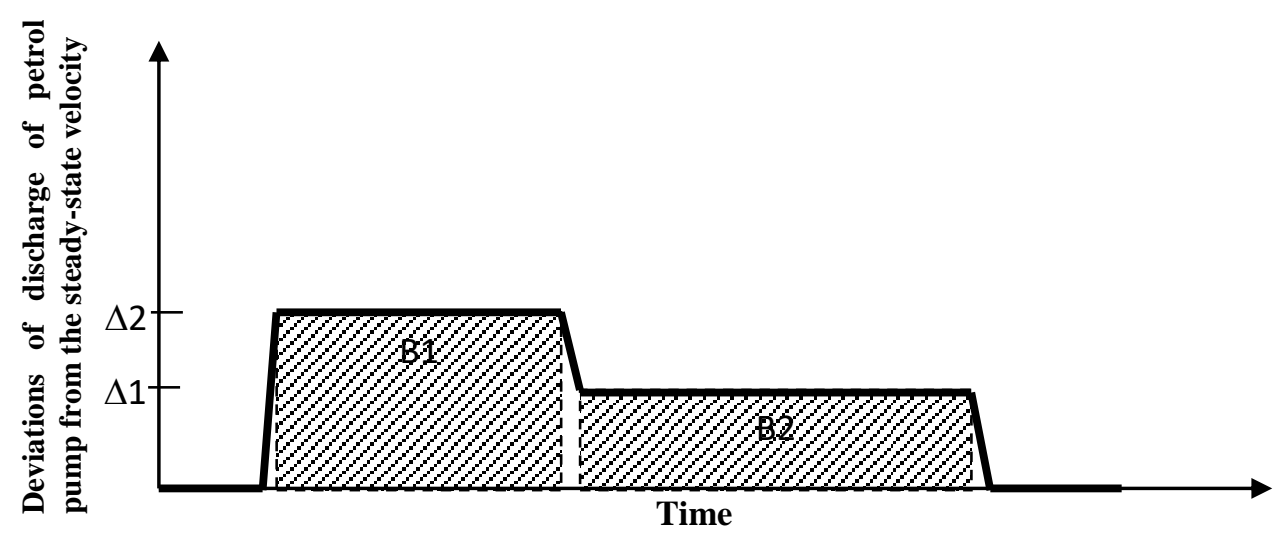

Fig. 4b: Illustration for the disturbance in the blending process (with regard to the deviations of the petrol flow velocity from the steady-state condition). 


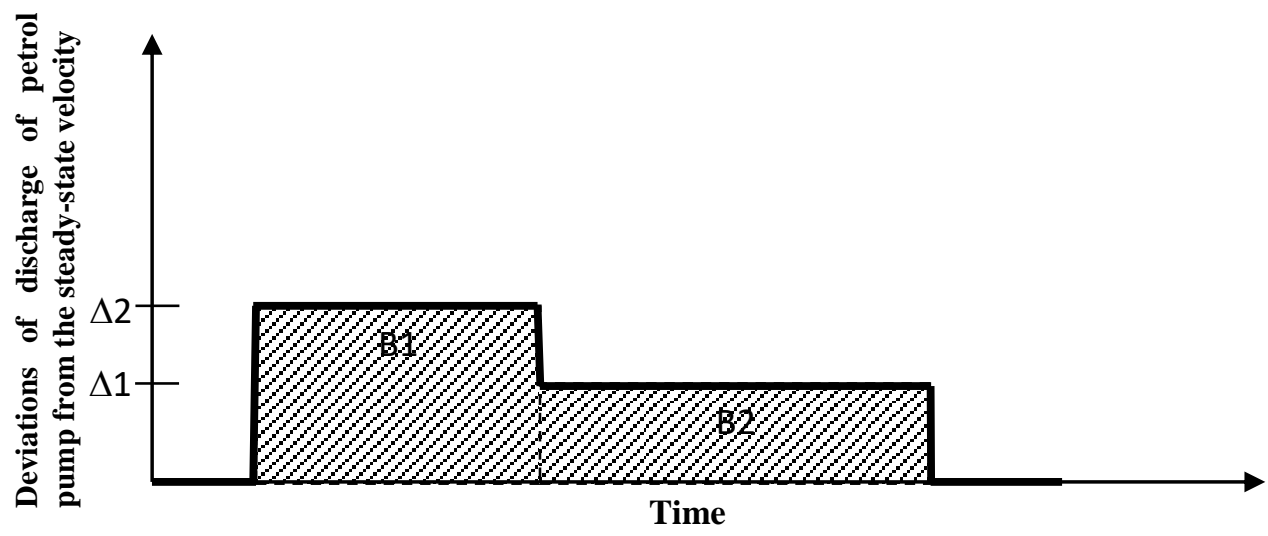

Fig. 4c: An approximation of the disturbance in the blending process (with regard to the deviations of the petrol flow velocity from the steady-state condition).

Figures 4 (a), (b) and (c) are based on the assumption that:

1. When the automobile engine is cranked, the petrol pump delivers petrol to the engine at a minimum steady flow velocity.

2. At the minimum steady flow velocity, the automobile engine runs at a base speed which is just sufficient to overcome the limiting frictional forces acting on the wheels.

3. The only disturbance in the blending process is the change in the variation in the discharge from the petrol pump. The changes in the discharge of the petrol pump give rise to the changes in the flow velocity of the inlet petrol.

4. The change in the flow velocity of the inlet petrol pump is impulsive and stochastic.

5. The profile for the discharge from the petrol pump for any given driving schedule can be illustrated as shown in Fig. 4a.

6. The bars, A1 and A2, represent the discharge from the petrol pump when the engine is revving - and they are representative of the zero-disturbance periods of the blending process.

7. The bars, B1 and B2, represent the discharge from the petrol pump during the motion-oriented periods of the blending process (i.e., when the engine is being throttled) - and they are representative of the disturbances in the blending process.

8. The profile of the pump discharge is composed of both non-uniform and uniform discharge regimes (as depicted by the unshaded and shaded parts of the graph, respectively).

9. The pump discharge is invariant when the engine is revving (as shown by A1 and A2) and varies markedly when the engine is throttled (as shown by bars B1 and B2).

10. Regardless of the quantity of petrol that is discharged by the petrol pump at any point in time, only the fraction of the discharge which is in excess of the pump discharge when the engine is revving (i.e., the portions of the B-bars which are above the A-bars) will constitute the disturbances in the blending process. This is illustrated in Fig. $4 \mathrm{~b}$ where

$$
\Delta 2=V_{3}-V_{1} \text { and, } \Delta 1=V_{2}-V_{1} \text {. }
$$

11. The non-uniform discharge regimes represent the short periods of time when the flow velocity of the inlet petrol is locally accelerated (or decelerated).

12. The effect of local acceleration on the disturbance in the blending process can be ignored, as shown in Fig. 4c.

Based on the profile of Fig. 4c, the disturbance in the blending process can be modeled by a series of pulse functions with differing amplitudes and periods [41].

\subsection{Analysing the Automatic Control System}

\subsubsection{Block Diagram Representation of the Automatic Control System}

The block diagram of the automatic control system was represented by analysing the diagram of the feedback control strategy separately and afterwards coupling the resulting block diagram to the feedforward control strategy. Figure 5 shows the block diagram representation of the feedback control system (without the feedforward control loop). Applying the methods of block diagram simplification, the feedback control loop (in Fig. 5) can be represented as shown in Fig. 6 where:

$G_{M}(s)=$ transfer function which describes how the output of the feedback controller for the density of the blended petrol affects the controlled variable

$$
G_{M}(s)=\frac{G_{c a}(s) G_{v}(s) G_{a}(s) H_{b}(s)}{1+G_{c a}(s) G_{v}(s) H_{a}(s)}
$$

$G_{D}(s)=$ transfer function which describes how the process disturbance, $V_{p}(s)$ affects the controlled variable

$$
G_{D}(s)=G_{P}(s) H_{b}(s)
$$

By coupling the resulting block diagram in Fig. 6 to the feedforward control loop, we have the diagram in Fig. 7 where: 


$$
C(s)=G_{D}(s) V_{p}(s)+H_{p}(s) F F C(s) G_{M}(s) V_{p}(s)
$$

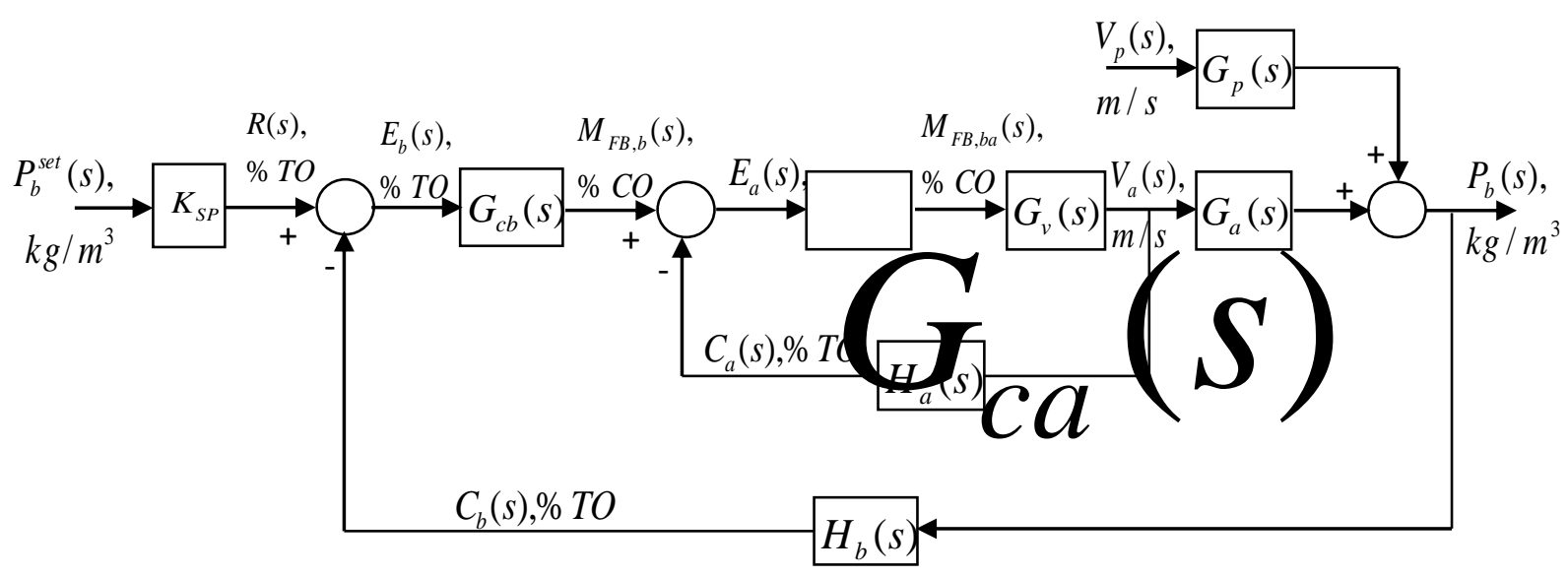

Fig. 5: Block diagram representation of the feedback control strategy.

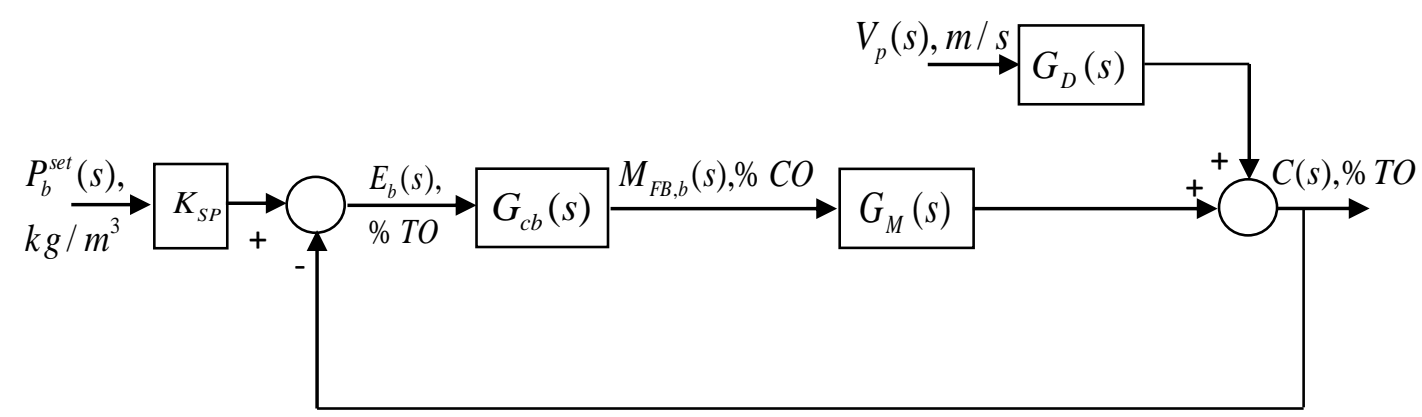

Fig. 6: Block diagram analysis of the feedback control strategy.

Since the objective is to design FFC such that a change in $V_{p}(s)$ does not affect $C(s)$, then let $C(s)$ be equal to zero. So that $F F C(s)=\frac{-G_{D}(s)}{H_{p}(s) G_{M}(s)}=\frac{-G_{p}(s)\left[1+G_{c a}(s) G_{v}(s) H_{a}(s)\right]}{H_{p}(s) G_{c a}(s) G_{v}(s) G_{a}(s)}$

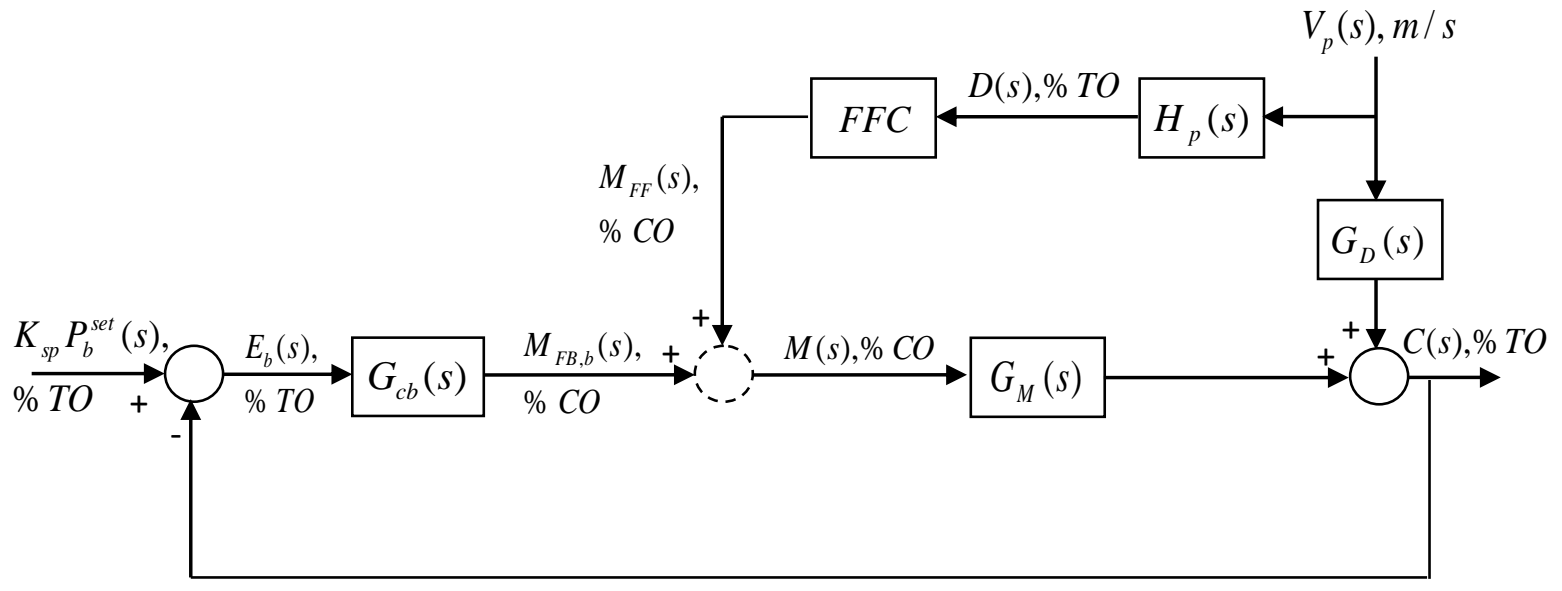

Fig. 7: Block diagram representation of the automatic control system. 
But

$$
F F C(s)=\frac{M_{F F}(s)}{D(s)}
$$

and

$$
D(s)=H_{p}(s) V_{p}(s)
$$

Hence,

$$
\begin{gathered}
M_{F F}(s)=\frac{-G_{p}(s) V p(s)\left[1+G_{c a}(s) G_{v}(s) H_{a}(s)\right]}{G_{c a}(s) G_{v}(s) G_{a}(s)} \\
M_{F F}(s)=\left[\frac{-\left[\frac{K_{11}\left(\tau_{2} s+1\right)-K_{13} K_{21}}{\left(\tau_{1} s+1\right)\left(\tau_{2} s+1\right)+K_{13} K_{23}}\right]\left\{1+\left[K_{c a}\left(1+\frac{1}{\tau_{i, c a} s}\right)\right]\left[\frac{K_{v}}{\tau_{v} s+1}\right]\left[\frac{K_{T a}}{\tau_{T a} s+1}\right]\right\}}{\left[K_{c a}\left(1+\frac{1}{\tau_{i, c a} s}\right)\right]\left[\frac{K_{v}}{\tau_{v} s+1}\right]\left[\frac{K_{12}\left(\tau_{2} s+1\right)-K_{13} K_{22}}{\left(\tau_{1} s+1\right)\left[\tau_{2} s+1\right]+K_{13} K_{23}}\right]} V_{p}(s)\right.
\end{gathered}
$$

The block diagram representation of the automatic control system in Fig. 7 can be simplified and resolved as Figs. $8 \mathrm{a}$ and $8 \mathrm{~b}$. Figure $8 \mathrm{~b}$ shows that the general expression which models the reaction of the automatic control system to the disturbance in the blending process is:

$$
C(s)=\left(\frac{G_{D}(s)+G_{M}(s) H_{p}(s) F F C}{1+G_{c b}(s)}\right) V_{p}(s)+\left(\frac{K_{s p} G_{c b}(s)}{1+G_{c b}(s)}\right) P_{b}^{s e t}(s)
$$

However, considering that the disturbance in the blending process is solely as a result of the changes in the flow velocity of the inlet petrol, $v_{p}(t)$ and that the set point of the density of the blended petrol, $\rho_{b}(t)$ is a pre-set value (which must not be altered); it is safe to conclude that the applicable transfer function which affects the performance of the blending process is given as:

$$
\begin{aligned}
& \frac{C(s)}{V_{p}(s)}=\frac{G_{D}(s)+G_{M}(s) H_{p}(s) F F C(s)}{1+G_{c b}(s)}
\end{aligned}
$$

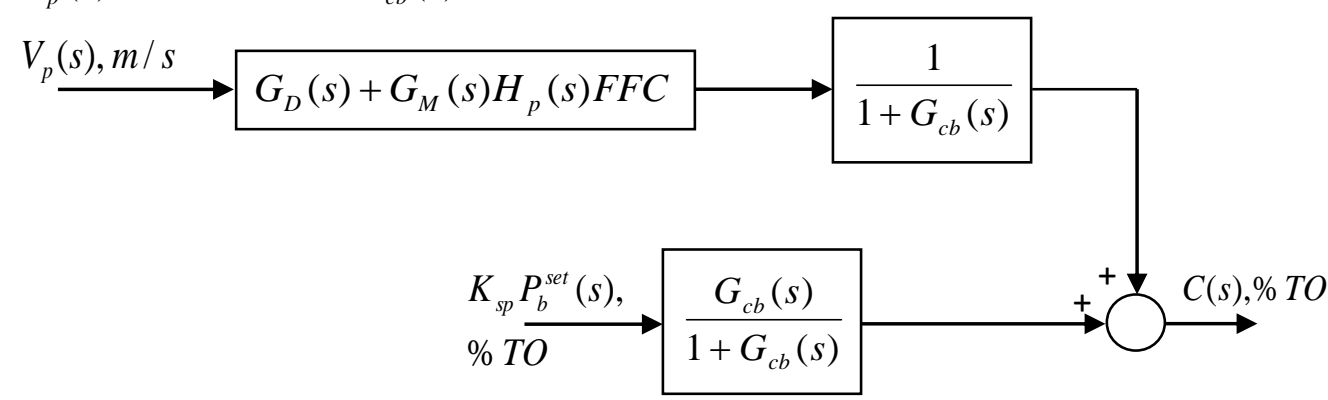

Fig. 8a: Simplified block diagram representation of the automatic control system.

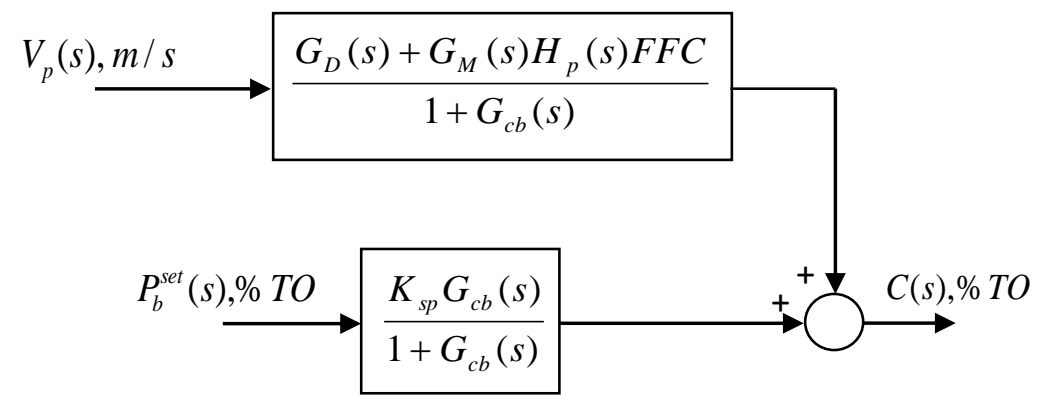

Fig. 8b: Further simplification of the block diagram representation of the automatic control system. 


\subsection{RESULTS AND DISCUSSION}

The stability of both the blending process and the automatic control system for the blending process were simulated using Simulink ${ }^{\circledR}$ in MATLAB. This was done by reproducing the block diagrams for the two processes on the Simulink model window, as shown in Figs. 9a and 9b. The MATLAB simulations of both the blending process and the automatic control system for the blending process are as shown in Figs. 10a, 10b (i), 10b (ii) and 10b (iii). While Fig. 10a shows the simulation of the blending process and the control system in the absence of a disturbance, Figs. 10b (i), 10b (ii) and 10b (iii) show the simulation of the blending process and the control system in the presence of some kind of disturbance. The plots of these simulations were obtained by assuming that all the gains, $K$ 's and time constants, $\tau$ 's in all the transfer function blocks (in Figs. 9a and 9b) are assigned the value of 1 . The simulation parameters for, $V_{p}(s), V_{a}(s)$ and $P_{b}^{s e t}(s)$ were defined such that, while $V_{p}(s)$ is a pulse function with amplitude $=1$ and phase delay $=0 ; V_{a}(s)$ and $P_{b}^{\text {set }}(s)$ are step functions with step time $=0$, initial value $=0$, final value $=1$, and sample time $=0$.

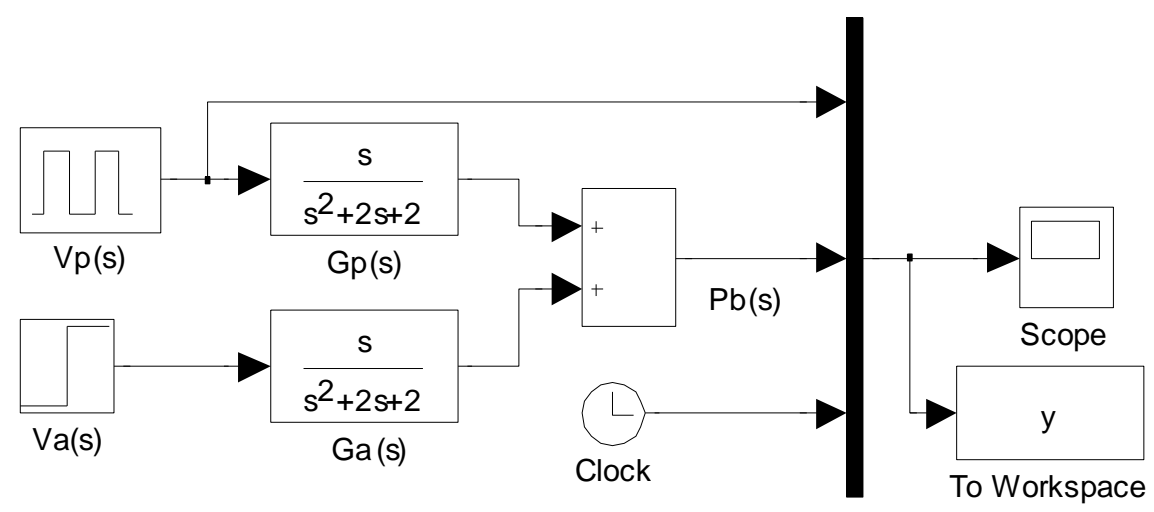

(a)

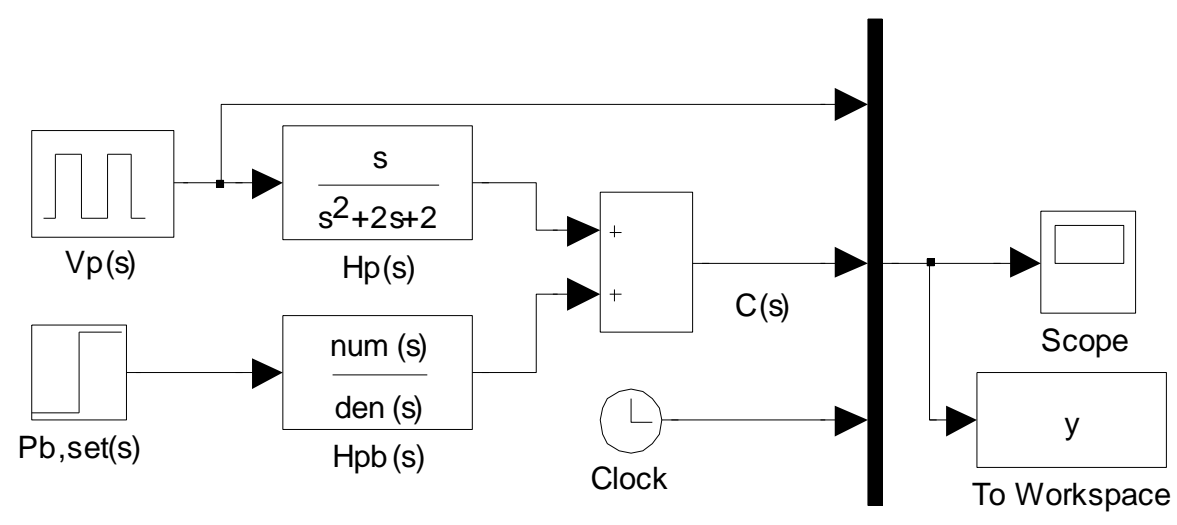

(b)

Fig. 9: MATLAB model for the block diagram representation of the response of (a) the blending process, (b) the control system.

In Fig. 9(b),

$\frac{\operatorname{num}(s)}{\operatorname{den}(s)}=\frac{-s^{11}-8 s^{10}-28 s^{9}-57 s^{8}-75 s^{7}-66 s^{6}-38 s^{5}-13 s^{4}-2 s^{3}}{2 s^{13}+19 s^{12}+85 s^{11}+236 s^{10}+451 s^{9}+622 s^{8}+631 s^{7}+470 s^{6}+251 s^{5}+91 s^{4}+20 s^{3}+2 s^{2}}$

As the engine is cranked, the blending process experiences a positive gain with a slight oscillation while the control system output experiences a negative gain without oscillation. The blending process will reach steady-state after about 5 secs (Fig. 10a). From that Fig 10a, it could be seen that the normalized maximum control error, after the blending process output reaches the 
set-point for the first time (i.e., maximum overshoot, $e_{\max }$ ), is approximately $32 \%$. This value does not vary so much from the recommended value of $25 \%$ for the majority of process control systems [42].

$$
e_{\max }=\frac{y_{\max }-y_{\infty}}{y_{\infty}} \times 100
$$

where $y_{\max }$ is the maximum gain and $y_{\infty}$ is the gain at infinite time. At the steady state, the gains of the blending process and the control system are zero.

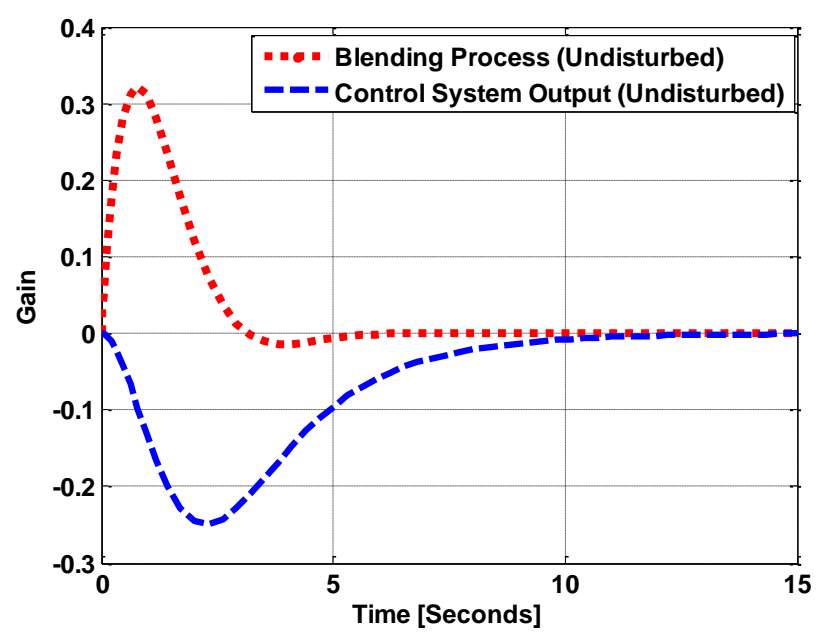

Fig. 10a: Behaviour of both the blending process and the control system in the absence of a disturbance.

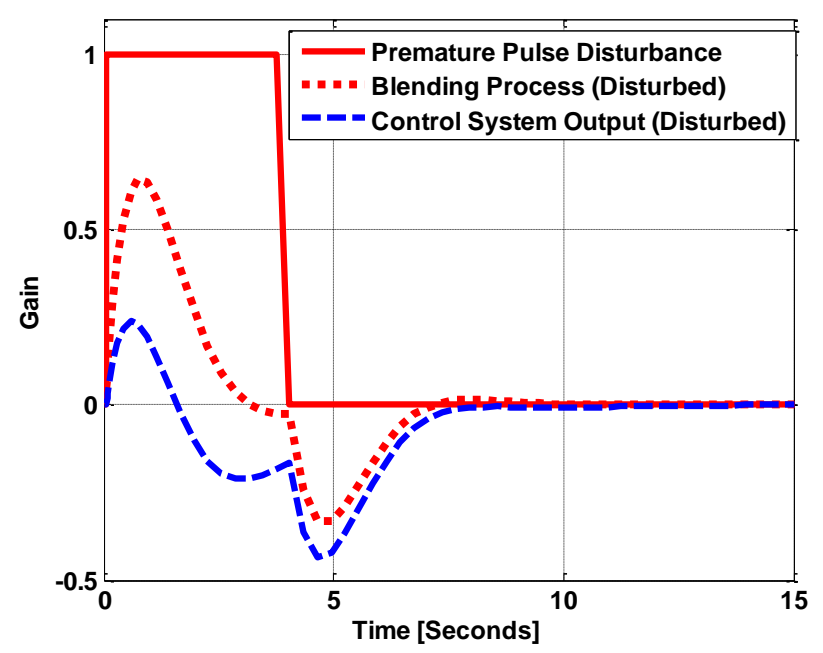

Fig. 10b (ii): Behaviour of both the blending process and the control system in the presence of a premature disturbance.

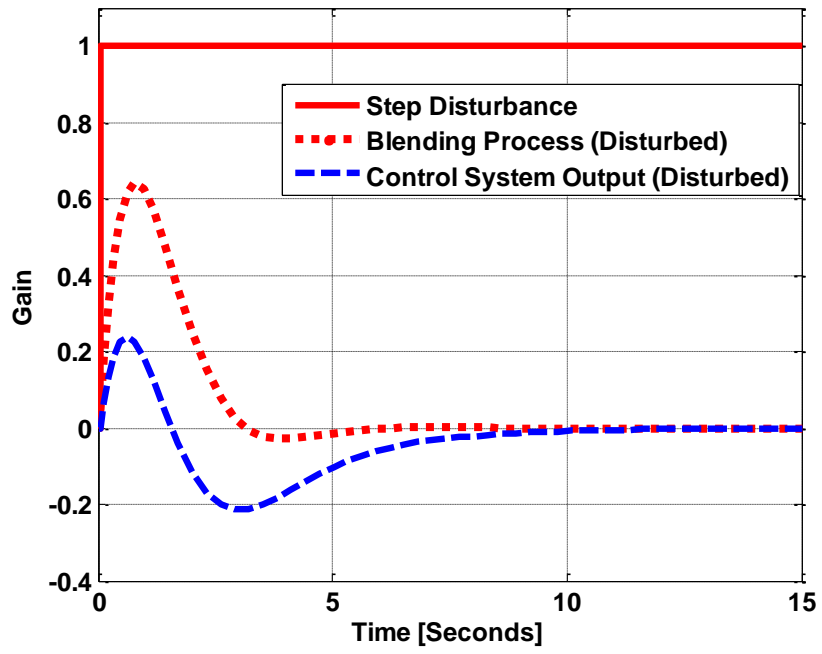

Fig. 10b (i): Behaviour of both the blending process and the control system in the presence of a disturbance.

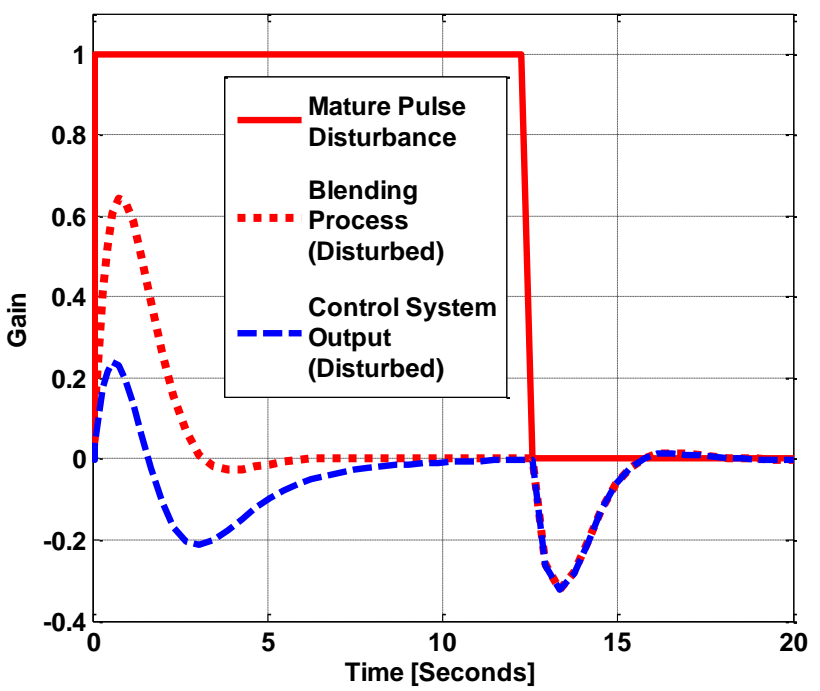

Fig. 10b (iii): Behaviour of both the blending process and the control system in the presence of a mature disturbance.

Fig. 10: Behaviour of both the blending process and the control system under different conditions.

When subjected to a pulse function (i.e., when the engine is being throttled), the maximum overshoot gets to about $62 \%$ as shown in Fig. 10b (i). It could be seen that although the presence of a step disturbance will increase the value of $e_{\text {max }}$, the time it takes the blending process to reach steadystate remains constant. The step disturbance causes the control system output to oscillate. However, both the blending process and the control system output reach steady state at about the same time. Hence for a continuous throttling of the system, both the blending process and the control system output will achieve stability at about the same time. 
Figures 10b (ii) and 10b (iii) show what happens when two different kinds of disturbances in the blending process are introduced. Figure 10b (ii), represents a situation where the throttling in the system is introduced and is quickly discontinued. Figure 10b (iii), represents a situation where the throttling in the system is introduced, sustained and is quickly discontinued. For both cases, the discontinuation of the pulse introduces a noticeable negative gain in the response of the blending process. However, it is noteworthy that the time it takes this negative gain to decay is approximately constant for the two different disturbances. The fact that the absolute value of the maximum gain of the output of the control system is always less than the absolute value of the maximum gain of the blending process (as clearly shown in all the figures) suggests that the output of the control system will be less sensitive to the disturbances in the flow velocity of the inlet petrol. This implies that the control system tries to compensate for the disturbances in the velocity of the inlet petrol, as much as possible, in order that its output (i.e., the density of the blended petrol) will not deviate markedly from the set-point value.

\subsection{CONCLUSION}

An automatic control system which could ensure the blending of petrol and corrosion inhibitor in a cranked automobile engine has been designed in this work. It has been shown that the set-point density of the blended petrol could be controlled regardless of the disturbance in the blending process. General expressions for the functions which modeled both the responses of the blending process and the automatic control system for the blending process were derived from first principles. Whereas the response of the automatic control system was analyzed using block diagrams; the stability of the control system was determined from computer simulation. The result of the computer simulation showed that even though the gain of the automatic control system for the blending process will have a negative value; the response of the control system will be parabolic and stable. Although the result of the simulation of the automatic control system for the blending process shows a negative gain; in reality, this is not the case. The negative gain of the automatic control system rather suggests that, in the actual design of the automatic control system, the feedback controller scaling factor, $K_{\mathrm{sp}}$ must be assigned a negative value. Finally, the analysis presented here could assist in further research in the online blending of petrol with additives in cranked automobile engines.

\section{DECLARATION OF CONFLICTING INTERESTS}

The authors declared no potential conflicts of interest with respect to the research, authorship and/or publication of this article.

\section{FUNDING}

The authors received no financial support for the research, authorship and/or publication of this article.

\section{REFERENCES}

[1] CIMAC. Fuel Quality Guide - Ignition and Combustion http://www.cimac.com/cms/upload/Publication_Press/WG_Pu blications/CIMAC_WG07_2011_Guideline_Fuel_Quality_Ign ition_Combustion.pdf (2011, accessed 29 October 2015).

[2] von Wielligh AJ, Burger NDL and de Vaal PL. Diesel injector failures and consequences caused by fuel quality - case studies. In: Proceedings, International Conference of the South African Institute of Tribology. http://www.sacea.org.za/.\%5Cdocs\%5CSAIT\%20Referaat $\% 20$ Inspuiters_2_Shrunk.pdf (2004, accessed 29 October 2015).

[3] Pandey BC, Ali SN and Paul A. Study of adulteration in transportation fuel. Int. J. Adv. Sci. Eng. Tech. 2016. Spl. Issue-1: 58-60.

[4] ABS. Notes on Heavy Fuel. www.eagle.org/eagleExternalPortalWEB/ShowProperty/BEA \%20Repository/Rules\&Guides/Current/31_HeavyFuelOil/Pub 31_HeavyFuelOil (1984, accessed 11 September 2016).

[5] American Public Works Association. 6.7L Diesel Fuel System Contamination Diagnosis and Services Procedure Job Aid http://www2.apwa.net//Documents/About/TechSvcs/6_7_Dies el_Fuel_System_Contamination_Diagnosis_and_Service_Proc edure_Job_Aid.pdf (2012, accessed 30 May 2016).

[6] Gard AS. Warning-Fuel Oil Quality Might be at Stake. Gardyourship, Loss Prevention Circular \#08-07. http://www.gard.no/Content/8061/No\%2008-07\%20WarningFuel\%20quality $\% 20$ might $\% 20$ be $\% 20$ at\%20stake.pdf $\quad(2007$, accessed 29 October 2015).

[7] Payri R, de la Morena J, Pagano V, et al. One-dimensional modeling of the interaction between close-coupled injection events for a ballistic solenoid injector. Int. J. Engine Res. 2019; 20(4): 452-469.

[8] Kimura K, Mori S, Kawauchi M, et al. An investigation for reducing combustion instability under cold-start condition of a direct injection gasoline engine. Int. J. Engine Res. 2019; 20(4): 470-479.

[9] EL-Kassaby MM, Eldrainy YA, Khidr ME, et al. Effect of hydroxy $(\mathrm{HHO})$ gas addition on gasoline engine performance and emissions. Alexandria Eng. J. 2016; 55: 243-251.

[10] Ma F, Wang M, Jiang L, et al. Performance and emission characteristics of a turbocharged spark-ignition hydrogenenriched compressed natural gas engine under wide open throttle operating conditions. Int. J. Hydrog. Energy 2010; 35(22): 12502-12509

[11] Shivaprasad KV, Raviteja S, Chitragar P, et al. Experimental investigation of the effect of hydrogen addition on combustion performance and emissions characteristics of a spark ignition high speed gasoline engine. Proc. Tech. 2014; 14: 141-148.

[12] Wang S, Ji C, Zhang B, et al. Performance of a hydroxygenblended gasoline engine at different hydrogen volume fractions in the hydroxygen. Int. J. Hydrog. Energy 2012; 37(17) 13209-13218.

[13] Wang S, Ji C, Zhang J, et al. Improving the Performance of a gasoline engine with the addition of hydrogen-oxygen mixtures, Int. J. Hydrog. Energy 2011; 36(17): 11164 - 11173.

[14] Chen JL, Chen G and Wells M. Dynamic and static flow analysis of a gasoline fuel injector, J. Eng. Gas Turbines Power 1993; 115(4): 750-755.

[15] Anatone M, Cipollone R, Sciarretta A, et al. Air/fuel modelbased control in spark-ignition internal combustion engines https://www.researchgate.net/publication/235248952_AirFuel_ Model_Based_Control_in_SI_Internal_Combustion_Engines (2005, accessed 30 May 2017).

[16] Maeda I and Kasugai J. Patent No. 5,806,480, U.S.A. https://www.google.com/patents/US5806480 (1998, accessed 30 May 2017).

[17] Vladaj TMP and Leconte VDJ. Patent No. 8,641,792 B2, U.S.A. https://www.google.com/patents/US8641792 (2014, accessed 30 May 2017).

[18] Niakan SN and Landel CL. Patent No. US D749134 S1, U.S.A. https://www.google.com/patents/USD749134 (2016, accessed 30 May 2017). 
[19] Tuccar G, Uludamar E and Aydın K. Optimization of fuel inlet port geometry of an air assisted diesel injector. Adv. Automob. Eng. 2016; 5: 158.

[20] Lindstorm M. Injector nozzle hole parameters and their influence on real di diesel performance. Royal Inst. Technol, Licentiate Thesis. http://www.divaportal.org/smash/get/diva2:159595/FULLTEXT01.pdf (2009, accessed 31 May 2017).

[21] Lorenzetto GE and Lefebvre AH. Measurements of drop size on a plain-jet air blast atomizer. Am. Inst. Aero. Astro. J. 1977; 15(7): 1006-1010.

[22] Lefebvre AH. Energy conservations in twin-fluid atomization J. Eng. Gas Turbines Power 1992; 114(1): 89-96.

[23] Watanawanyoo P, Hirahara H, Mochida H, et al. Experimental Investigations on Spray Characteristics in Twin-Fluid Atomizer. Proc. Eng. 2011; 24: 866-872.

[24] Tüccar G, Özgür T, Tosun E, et al. Investigation of effects of inlet boundary conditions on the flow behavior in a diesel injector, Adv. Mat. Res. 2014; 1016: 602-606.

[25] Tomizuka $M$ and Fung DH. Design of digital feedforward/preview controllers for processes with predetermined feedback controllers, J. Dyn. Syst., Meas., Control 1980; 102(4): 218 - 225 .

[26] Sworder DD. Control of systems subject to small measurement disturbances. J. Dyn. Syst., Meas., Control 1984; 106(2): 182188.

[27] Yang WC, Glidewell JM, Tobler WE, et al. Dynamic modelling and analysis of automotive multi-port electronic fuel delivery system. J. Dyn. Syst., Meas., Control 1991; 113(1): 143-151.

[28] Kao M and Moskwa JJ. Turbocharged diesel engine modeling for nonlinear engine control and state estimation, J. Dyn. Syst., Meas., Control 1995; 117(1): 20-30.

[29] Powell BK, Cook JA and Grizzle JW. Modeling and analysis of an inherently multi-rate sampling fuel injected engine idle speed control loop. J. Dyn. Syst., Meas., Control 1987; 109(4): 405-410.

[30] Archer M and Bell G. Advanced electronic fuel injection systems - an emissions solution for both 2- and 4-stroke small vehicle engines. SAE paper 2001-01-0010, 2001.

[31] Yang HQ, Shuai SJ, Wang Z, et al. Gasoline multiple premixed compression ignition (MPCI): controllable, high efficiency and clean combustion mode in direct injection engines. Int. J. Automot. Technol. 2013; 14(1): 19-27.

32] Chung JW, Kang JH, Kim NH, et al. Effects of the fue injection ratio on the emission and combustion performances of the partially premixed charge compression ignition combustion engine applied with the split injection method. Int J. Automot. Technol. 2008; 9(1): 1-8.

[33] Tumbal AV, Banapurmath NR and Tewari PG. Effect of injection timing, injector opening pressure, injector nozzle geometry, and swirl on the performance of a direct injection, compression-ignition engine fueled with honge oil methyl ester (HOME), Int. J. Automot. Technol. 2016; 17(1): 35-50.

34] Passarini LC and Pinotti M Jr. A new model for fast-acting electromagnetic fuel injector analysis and design. J. Braz. Soc. Mech. Sci. Eng. 2003; 25(1): 95-106.

[35] Lee SH, Howlett R and Walters SD. Small engine control by fuzzy logic. J. Intel Fuzzy Syst. 2004; 15(3): 207-217.

[36] Robinson Y and Dhandapani S. Experimental investigation on electronic fuel injection in a 2-stroke, spark-ignition engine by virtual instrumentation technique. Int. J. Eng. Edu. 2005; 21(1): 55-62.

[37] Tan CW, Selamat H and Alimin A. Modeling and Control of an Engine Fuel Injection System. Int. J. Simulat., Syst., Sci. Technol. 2010; 11(5): 48-60.

[38] Mastanaiah M. Performance of electronic fuel injection systems using compressor and controller. Int. J. Adv. Eng. Res. Studies, 2013; 2(3): 57-59.

[39] Osueke CO and Ofondu IO. Fuel Adulteration in Nigeria and its Consequences. Int. J. Mech. Mechatron. Eng. 2011; 11(4) 32-35.

[40] Nam EK and Giannelli R. Fuel Consumption Modelling of Conventional and Advanced Technology Vehicles in the Physical Emission Rate Estimator (PERE). https://www3.epa.gov/otaq/models/ngm/420p05001.pdf (2005, accessed 8 September 2015).

[41] Smith CA and Carripio A. Principles and practice of automatic process control. 3rd ed. New York: John Wiley \& Sons, Inc., 2006.

[42] Mikles J and Fikar M. Process modelling, identification and control. New York: Springer, 2007.

\section{NOMENCLATURE}

$A_{a}=$ Cross sectional area of the additive pipeline $\left[\mathrm{m}^{2}\right]$

$A_{b}=$ Cross sectional area of the blended petrol pipeline $\left[\mathrm{m}^{2}\right]$

$A_{p}=$ Cross sectional area of the inlet petrol pipeline $\left[\mathrm{m}^{2}\right]$

$A C=$ Additive flow velocity controller

$\alpha=$ Valve rangeability parameter

$\% C O=$ Percentage of controller output

$c(t)=$ Sensor/transmitter output signal

$C(t)=$ Deviation of a sensor/transmitter output signal from its initial steady state value

$C(s)=$ Laplace transform of a sensor/transmitter output signal

$C_{a}(s)=$ Laplace transform of the output of a sensor/transmitter for the density of the blended petrol

$C_{b}(s)=$ Laplace transform of the output of a sensor/transmitter for the velocity of the additive

$C_{v}=$ Control valve coefficient

$C_{v, \max }=$ Maximum value of valve coefficient

$D(s)=$ Output signal of the feedforward sensor/transmitter

$e(t)=$ Error signal 
$E(t)=$ Deviation of the error signal from its initial steady state value

$E(s)=$ Laplace transform of the error signal

$E_{a}(s)=$ Laplace transform of the error signal in the controller of the additive flow velocity

$E_{b}(s)=$ Laplace transform of the error signal in the controller of the blended petrol density

$F C=$ Flow controller for the additive flow velocity

$F F C=$ Feedforward controller

$F F C(s)=$ Laplace transform of the transfer function of the feedforward controller

$F(s)=$ Laplace transform of the flow (output) from a control valve

$F_{x}=$ External force acting on the control volume along the $\mathrm{x}$-axis

$F T_{a}=$ Sensor/transmitter for the flow velocity of the additive.

$F T_{p}=$ Sensor/transmitter for the flow velocity of the inlet petrol

$F Y=$ Control system summing device

$G_{c}(s)=$ Transfer function of a controller

$G_{c a}(s)=$ Transfer function of the feedback controller for the flow velocity of the additive

$G_{c a a}(s)=$ Transfer function which describes how the flow velocity of the additive is affected by the feedback controller for the density of the blended petrol

$G_{c b}(s)=$ Transfer function of the feedback controller for the density of the blended petrol

$G_{D}(s)=$ Transfer function which describes how the process disturbance affects the controlled variable (i.e. the density of the blended petrol)

$G_{M}(s)=$ Transfer function which describes how the output of the feedback controller for the density of the blended petrol affects the controlled variable

$G_{T}(s)=$ Transfer function of a sensor/transmitter device

$G_{V}(s)=$ Transfer function of a control valve

$H=$ Any arbitrary real number

$h_{a}=$ Enthalpy of the additive

$H_{a}(s)=$ Transfer function of the sensor/transmitter for the flow of the additive

$h_{b}=$ Enthalpy of the blended petrol

$H_{b}(s)=$ Transfer function of the sensor/transmitter for the density of the blended petrol

$h_{p}=$ Enthalpy of the inlet petrol

$H_{p}(s)=$ Transfer function of the sensor/transmitter for the flow velocity of the inlet petrol

$K=$ Engine friction factor

$K_{c}=$ Controller gain

$K_{c a}=$ Gain of the additive controller

$K_{s p}=$ Controller scale factor

$K_{T}=$ Transmitter gain

$K_{T a}=$ Gain of the additive sensor/transmitter

$K_{T p}=$ Gain of the inlet petrol sensor/transmitter

$K_{v}=$ Control valve gain

$K_{11}=$ Steady state gain for the conservation of mass in the blending process, with respect to changes in the flow velocity of the inlet petrol, $\mathrm{V}_{\mathrm{p}}(t)$ 
$K_{12}=$ Steady state gain for the conservation of mass in the blending process, with respect to changes in the flow velocity of the additive, $\mathrm{V}_{\mathrm{a}}(t)$

$K_{13}=$ Steady state gain for the conservation of mass in the blending process, with respect to changes in the flow velocity of the blended petrol, $\mathrm{V}_{\mathrm{b}}(t)$

$K_{21}=$ Steady state gain for the conservation of the combined equation of x-momentum and energy in the blending process with respect to changes in $\mathrm{V}_{\mathrm{p}}(t)$

$K_{22}=$ Steady state gain for the conservation of the combined equation of x-momentum and energy in the blending process with respect to changes in $\mathrm{V}_{\mathrm{a}}(t)$

$K_{23}=$ Steady state gain for the conservation of the combined equation of x-momentum and energy in the blending process with respect to changes in $\mathrm{V}_{\mathrm{b}}(t)$

$L H V=$ Lower heating value of petrol $[\mathrm{kJ} / \mathrm{g}]$

$\zeta=$ Laplace transform notation

$M(s)=$ Laplace transform of the manipulated signal

$m(t)=$ Manipulated (controller output) signal

$m_{F B, b}(t)=$ Feedback manipulated signal for the control of the density of the blended petrol

$m_{F B, b a}(t)=$ Feedback manipulated signal for the control of the density of the blended petrol and the control of the flow velocity of the additive

$m_{F F}(t)=$ Feedforward manipulated signal for the control of the flow velocity of the inlet petrol

$M_{F B, b}(s)=$ Laplace transform of the output of the feedback controller for the density of the blended petrol

$M_{F B, b a}(s)=$ Laplace transform of the output of the feedback controller for both the density of the blended petrol and the flow velocity of the additive

$M_{F F}(s)=$ Laplace transform of the feedforward manipulated signal for the control of the flow velocity of the inlet petrol

$M F R=$ Mass flow rate of petrol

$N=$ Engine speed $[\mathrm{rpm}]$

$\eta=$ Engine indicated efficiency

$\eta_{t}=$ Engine transmission and final drive efficiency

$P_{a c c}=$ Power draw of car accessories [W]

$P_{b}=$ Engine brake power $[\mathrm{W}]$

$P_{b}(s)=$ Laplace transform of the deviation of the density of the blended petrol from its initial steady state value

$P_{b}^{s e t}(s)=$ Laplace transform of the set point density of the blended petrol

$P_{b}(t)=$ Deviation of the density of the blended petrol from its initial steady state value

$P C=$ Density controller for the blended petrol

$P T=$ Sensor/transmitter for the density of the blended petrol

$P V(s)=$ Laplace transform of a process variable

$\rho_{a}(t)=$ Density of the additive $\left[\mathrm{kg} / \mathrm{m}^{3}\right]$

$\bar{\rho}_{b}=$ Initial steady state value of the blended petrol density

$\rho_{b}^{\text {set }}(t)=$ Set point density of the blended petrol $\left[\mathrm{kg} / \mathrm{m}^{3}\right]$

$\rho_{b}(t)=$ Density of the blended petrol $\left[\mathrm{kg} / \mathrm{m}^{3}\right]$

$\rho_{p}(t)=$ Density of the inlet petrol $\left[\mathrm{kg} / \mathrm{m}^{3}\right]$

$Q=$ Flow discharge $\left[\mathrm{m}^{3} / \mathrm{sec}\right]$ 
$\dot{Q}=$ Rate of heat flow into a control volume $[\mathrm{J} / \mathrm{sec}]$

$\varphi=$ Petrol/air equivalence ratio

$r(t)=$ Reference signal (set point signal) [\% $\%$ ]

$R(t)=$ Deviation of the reference signal from its initial steady state value

$R(s)=$ Laplace transform of the reference signal

$s=$ Laplace transform variable

$\mathrm{t}=$ Time [mins]

$\mathrm{t}_{0}=$ Initial time [mins]

$T=$ Discrete time interval [mins]

$\% T O=$ Percentage of transmitter output

$\tau_{D}=$ Derivative (or rate) time [mins]

$\tau_{i}=$ Integral (or reset) time [mins]

$\tau_{i, c a}=$ Integral time of the additive controller [mins]

$\tau_{T}=$ Transmitter time constant [mins]

$\tau_{T a}=$ Time constant of the sensor/transmitter for the flow velocity of the additive [mins]

$\tau_{T p}=$ Time constant of the sensor/transmitter for the flow velocity of the inlet petrol [mins]

$\tau_{v}=$ Control valve time constant [mins]

$\tau_{1}=$ Time constant for the conservation of mass in the blending process [mins]

$\tau_{2}=$ Time constant for the conservation of the combined equation of $\mathrm{x}$-momentum and energy in the blending process

$v_{a}(t)=$ Flow velocity of the additive $[\mathrm{m} / \mathrm{sec}]$

$v_{b}(t)=$ Flow velocity of the blended petrol $[\mathrm{m} / \mathrm{sec}]$

$\bar{v}_{b}=$ Initial steady state value of the flow velocity of the blended petrol $[\mathrm{m} / \mathrm{sec}]$

$v_{p}(t)=$ Flow velocity of the inlet petrol $[\mathrm{m} / \mathrm{sec}]$

$v=$ Volume of the control volume $\left[\mathrm{m}^{3}\right]$

$v_{e}=$ Volume of the engine piston displacement $\left[\mathrm{m}^{3}\right]$

$v_{i a}=$ Actual volume of the additive in the blended petrol $\left[\mathrm{m}^{3}\right]$

$v_{i p}=$ Actual volume of the inlet petrol in the blended petrol $\left[\mathrm{m}^{3}\right]$

$V_{a}(t)=$ Deviation of the flow velocity of the additive from its initial steady state value $[\mathrm{m} / \mathrm{sec}]$

$V_{a}(s)=$ Laplace transform of the deviation of the flow velocity of the additive from its initial steady state value

$V_{b}(t)=$ Deviation of the flow velocity of the blended petrol from its initial steady state value [m/sec]

$V_{b}(s)=$ Laplace transform of the deviation of the flow velocity of the blended petrol from its initial steady state value $v p=$ Valve position

$V_{p}(t)=$ Deviation of the flow velocity of the inlet petrol from its initial steady state value $[\mathrm{m} / \mathrm{sec}]$

$V_{p}(s)=$ Laplace transform of the deviation of the flow velocity of the inlet petrol from its initial steady state value $\dot{W}=$ Rate of work done by a control volume $[\mathrm{J} / \mathrm{sec}]$ 